Article

\title{
Influence of the Molar Mass on Long-Chain Branching of Polypropylene
}

\author{
Florian Kamleitner ${ }^{1, *}$ (D), Bernadette Duscher ${ }^{1}$, Thomas Koch ${ }^{1}$, Simone Knaus ${ }^{2}$, \\ Klaus Schmid ${ }^{3}$ and Vasiliki-Maria Archodoulaki ${ }^{1}$ \\ 1 Institute of Material Science and Technology, TU Wien, Getreidemarkt 9, Vienna 1060, Austria; \\ bernadette.duscher@tuwien.ac.at (B.D.); thomas.koch@tuwien.ac.at (T.K.); \\ vasiliki-maria.archodoulaki@tuwien.ac.at (V.-M.A.) \\ 2 Institute of Applied Synthetic Chemistry, TU Wien. Getreidemarkt 9, Vienna 1060, Austria; \\ simone.knaus@tuwien.ac.at \\ 3 Pergan GmbH, Schlavenhorst 71, Bocholt 46395, Germany; dr.schmid@pergan.com \\ * Correspondence: florian.kamleitner@tuwien.ac.at; Tel.: +43-(1)-58801-30869
}

Received: 21 August 2017; Accepted: 11 September 2017; Published: 12 September 2017

\begin{abstract}
Long-chain branching (LCB) with peroxydicarbonates (PODIC) is known as a suitable post-reactor process to introduce strain-hardening behaviour and an increase of melt strength to a linear polypropylene (PP). This opens up new possibilities for processing and therefore application. Especially in the case of adding value to PP post-consumer waste, LCB is a promising approach. LCB takes place by a combination of chain scission and recombination after radical activation of the PP macromolecule. However, chemical modification of post-consumer waste is challenging because of the inhomogeneous composition and the manifold number of PP grades. The influence of the molar mass of the linear PP precursor on this reaction was studied with different PP grades ranging from extrusion grade to injection moulding grade. To exclude side effects, all PP grades had similar polydispersity indices. A PP with higher molar mass undergoes significant chain scission during the LCB process compared to a PP with low molar mass for injection moulding. Therefore, the two grades differ significantly in their branching number, which influences their behaviour in elongational flow.
\end{abstract}

Keywords: long-chain branching; polypropylene; recycling

\section{Introduction}

Isotactic polypropylene (PP) is one of the most popular consumer plastics in the global polymer market. Its applications include plastic pipes, injection-moulded building parts, chill-rolled and blow-moulded films, fibres, thermoforming, etc. Regarding other thermoplastics, PPs' desirable properties like low density, high melting temperature, moderate stiffness and low cost make it the plastic with the second largest share in global plastic production [1,2]. Conspicuously, most applications of PP are designated only for short-term single use. As a result, a big share of the produced PP ends up quickly in post-consumer plastic waste. Establishing viable recycling processes is still a challenge as most PP post-consumer waste is incinerated or goes to landfill [3].

Mechanical recycling requires reliable analytical methods for quality assessment but would be the method of choice for the reintroduction of post-consumer waste PP in the manufacturing process of new PP products [4]. For example, the recycling of lead and PP from car batteries is a successful concept [5]. However, these processes are limited as PP is prone to photo-oxidation and degradation processes during its lifetime and mainly during the re-processing procedure due to the presence of tertiary carbons [6-9]. PP post-consumer waste collected from municipal household waste is a commingled feedstock with irregular composition. The impurities in PP post-consumer waste can be categorised into four groups: high molecular impurities like other plastics; low molecular impurities like different 
stabilisers; homo molecular impurities like PPs with different molar masses, or co-polymers; and inorganic impurities like fillers or metals $[10,11]$. While plastics with significant higher densities like polyethylene terephthalate (PET) and polyvinylchloride (PVC) can be separated by flotation in water, the similar densities of polyethylene (PE) and PP impede a simple separation [12]. For the reuse of PP/PE-fractions, compatibilisers like ethylene-propylene-rubber (EPR) are added to reduce negative influences from the immiscibility of PE and PP $[13,14]$. In the literature, concepts like in situ compatibilisation of PP/PE blends are shown to be attractive and cheap alternatives. Reactive monomers and/or peroxides are used to generate interfacial crosslinks to improve the mechanical properties of the polyolefin blends [15-22]. The kinetics of such grafting reactions is of great interest and so they have been studied intensively. A novel kinetic Monte Carlo strategy was recently presented by Hernández-Ortiz et al. to model the event history of grafting reactions [23].

In order to introduce long-chain branches (LCB) in linear isotactic PP, similar combinations of monomers and peroxides are used. LCB is a well-studied topic in the literature and numerous possibilities have been offered to find an efficient process to compensate for the loss of mechanical properties during recycling [24-34]. LCB in general results in an increase in the molar mass, a broadening of the molar mass distribution, an acceleration of crystallisation and an increase of the melt strength as well as strain hardening [34-38]. In case of PP, the property profile is extended due to the increased melt strength and special product applications, such as foaming and film blowing [39]. A suitable method to get LCB-PP from a linear isotactic PP homopolymer was presented by Lagendijk et al. They used peroxydicarbonates (PODIC), a special class of peroxides, to generate PP with an LCB structure [40]. PODICs with long aliphatic side chains (e.g., di-myristyl-peroxydicarbonate) are well described in a later work to give a high branching efficiency [41]. The PODIC acts as both initiator and co-agent and mediates partial chain scission and radical stabilisation for a successful branching reaction. A general reaction scheme is given in Figure 1.

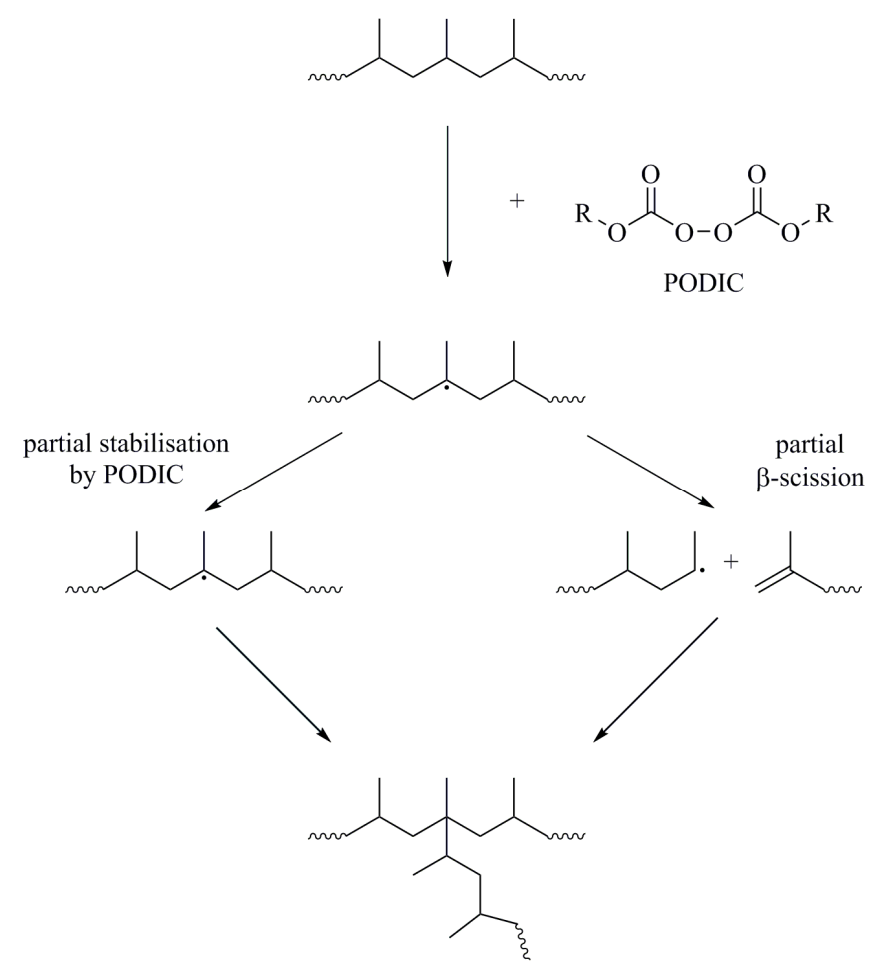

Figure 1. Reaction scheme of LCB process assisted by PODIC, according to Lagendijk et al.

A detailed study of the PODIC-mediated LCB reaction in melt has not been provided yet. In general, two alkoxy carbonyloxyl radicals are formed by a homolytic cleavage of the $\mathrm{O}-\mathrm{O}$ bond 
(II). In case of a sufficiently long time interval, (II) may decarboxylate by eliminating carbon dioxide, producing two alkoxy radicals (III) (Figure 2). In the case of di-myristyl-peroxydicarbonate, Buback et al. showed a high stability of species (II) [42]. Species (III) is expected to abstract hydrogen from the PP generating the PP macroradical. The improvement in melt strength is ascribed to the stabilisation of the PP macroradical due to the recombination with (II) and the formation of an alkylcarbonate-polymer adduct [43].

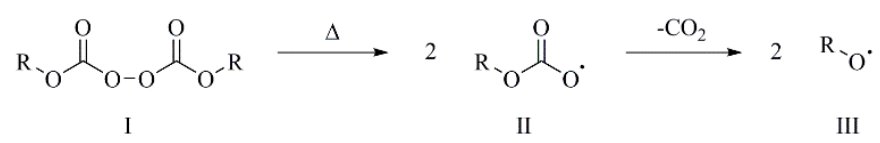

Figure 2. Decomposition of PODIC.

It could be shown that LCB is a suitable concept to improve the melt properties of PP from post-consumer waste with PE impurities, which is why one can speak of a real upcycling process [44]. The method of using PODIC and reactive extrusion is of special interest as it may be applied directly by the plastic manufacturer on recycled linear PP. However, LCB as an innovative recycling process is more promising when used for the modification of single polymer waste, because impurities like PEHD in PP post-consumer waste limit the number of possible applications of the upcycled product [45]. Nevertheless, even recycled single-polymer waste is a commingled resource of inhomogeneous composition. On the one hand, thermally and mechanically degraded PP resulting from reprocessing procedures has a high MFI, which influences the mechanical and flow properties [46,47]. On the other hand, single PP post-consumer waste contains different PP grades from different applications and therefore PPs with different molar masses. The molar mass is an important factor for the physical and mechanical properties of a polymer. For semi-crystalline thermoplastics, a higher molar mass induces an increasing number of inter- or intramolecular entanglements, a higher number of secondary bonds per volume, and changes of near- and long-range order. This directly influences the ability to crystallise, the elastic modulus and stiffness above glass transition temperature, as well as the flow properties in melt [48]. Therefore, the influence of PP grades of different molar mass on the LCB reaction and the number of $\mathrm{LCB}$ according to Lagendijk et al. in relation to the molar mass will be the topic of this study. In order to exclude any confounding effect of polydispersity, samples with similar $M_{\mathrm{w}} / M_{\mathrm{n}}$ ratios were used.

\section{Experimental Section}

\subsection{Materials}

Four different isotactic PP homopolymers supplied by Borealis (Vienna, Austria) were used for the study. PP 1 (HA 104E, Borealis, Vienna, Austria) is a high molar mass extrusion grades for pipe systems, PP2 (HC 600TF) is intended for thermoforming applications, PP3 (HD 601CF, Borealis, Vienna, Austria) is a film resin for chill roll processes, and PP4 (HF 700SA, Borealis, Vienna, Austria) is a PP grade for injection moulding. The different PPs differ only in their molar mass $\left(M_{\mathrm{w}}\right.$ and $\left.M_{\mathrm{n}}\right)$, but have similar dispersities $\left(M_{\mathrm{w}} / M_{\mathrm{n}}\right)$. Their rheological and molecular data are summarised in Table 1 .

Table 1. Rheological and molecular data of the PPs used as raw materials for the study.

\begin{tabular}{cccccc}
\hline Sample & $\mathbf{M F I}^{\mathbf{a}}[\mathbf{g} / \mathbf{1 0} \mathbf{~ m i n}]$ & $\boldsymbol{\eta}_{\mathbf{0}}[\mathbf{P a} \cdot \mathbf{s}]$ & $\boldsymbol{M}_{\mathbf{w}}\left[\mathbf{k g ~ \mathbf { ~ m o l } ^ { - \mathbf { 1 } } ]}\right.$ & $\boldsymbol{M}_{\mathbf{n}}\left[\mathbf{k g ~ \mathbf { ~ m o l } ^ { - \mathbf { 1 } } ]}\right.$ & $\boldsymbol{M}_{\mathbf{w}} / \boldsymbol{M}_{\mathbf{n}}$ \\
\hline PP1 & 0.75 & 56600 & 559 & 321 & 1.74 \\
PP2 & 2.8 & 17700 & 394 & 198 & 1.99 \\
PP3 & 8 & 5900 & 300 & 151 & 1.99 \\
PP4 & 21 & 2140 & 227 & 99 & 2.29 \\
\hline \multicolumn{5}{c}{ a provided in the product data sheet. }
\end{tabular}

${ }^{a}$ provided in the product data sheet. 
PODIC (a white powder) Peroxan C126 (Pergan, Schlavenhorst, Germany) (Di-tetradecylperoxydicarbonate; $10 \mathrm{~h}$ half-life at $48^{\circ} \mathrm{C}$ ) was supplied by Pergan (Schlavenhorst, Germany).

\subsection{Thermal Analysis}

A standard procedure with TA Instruments (TA) standard aluminium pans (5 mg sample mass) on a TA Q2000 DSC (TA instruments, Newcastle, DE, USA) was used for thermal analysis. Samples were heated to $200^{\circ} \mathrm{C}\left(10^{\circ} \mathrm{C} \cdot \mathrm{min}^{-1}\right)$, cooled down to room temperature and heated up again to $200^{\circ} \mathrm{C}$ at the same rate. TA Universal analysis software (TA instruments, Newcastle, DE, USA) was used to determine melting $\left(T_{\mathrm{m}}\right)$ and crystallisation temperature $\left(T_{\mathrm{c}}\right)$, as well as the melting enthalpy $\left(\Delta H_{\mathrm{m}}\right)$.

Oxidation induction time (OIT) was determined according to DIN ISO 11357-6 [49]. The samples were heated up in open pans to $200{ }^{\circ} \mathrm{C}\left(10^{\circ} \mathrm{C} \cdot \mathrm{min}^{-1}\right)$ under a nitrogen atmosphere. Then the purging gas was changed to air and the temperature was kept at $200^{\circ} \mathrm{C}$ for $90 \mathrm{~min}$.

\subsection{Molar Mass Determination}

The determination of the molar mass distribution (MMD) was carried out on a Viscotek High Temperature size exclusion chromatography (HT-SEC) system (Malvern instruments, Herrenberg, Germany) at $140{ }^{\circ} \mathrm{C}$ with 1,2,4-Trichlorobenzene as eluent and standard triple detection (refractive index, low angle light scattering and capillary viscometer).

\subsection{Rheology}

Discs with $25 \mathrm{~mm}$ diameter and $1.2 \mathrm{~mm}$ thickness for dynamic rheology were compression moulded at $20 \mathrm{bar}$ and $180^{\circ} \mathrm{C}$. Dynamic rheology measurements were carried out on a plate-plate Anton Paar MCR 301 rheometer (Anton Paar, Graz, Austria) equipped with a CTD 450 heating chamber (Anton Paar, Graz, Austria) under nitrogen at $180^{\circ} \mathrm{C}$ with $1 \mathrm{~mm}$ gap size. The frequency range was set from 628 to $0.01 \mathrm{rad} \cdot \mathrm{s}^{-1}$ and deformation was raised logarithmically from $1 \%$ to $2 \%$ during the measurement. All measurements were performed within the linear viscoelastic region and thermal stability was checked by time sweep experiments at $180{ }^{\circ} \mathrm{C}$ for $2 \mathrm{~h}$. The zero-shear viscosity $\eta_{0}$ of the samples was determined by measuring the creep compliance at $180{ }^{\circ} \mathrm{C}$ at a constant stress $\tau$ of 5 and $30 \mathrm{~Pa}$. For small stresses, there is a linear range, whereby the creep compliance $J(t, \tau)$ reaches a stationary state and the zero-shear viscosity can be determined from the plateau of $t / J$ when it is plotted against $t$.

$$
\eta_{0}=\lim _{t \rightarrow \infty}\left(\frac{t}{J(t, \tau)}\right)
$$

This is shown in Figure 3 for PP1 and PP1-LCB.

\subsection{Extensional Rheology}

Stripes with $8 \mathrm{~mm}$ width for extensional rheology were cut from $100 \mathrm{~mm} \times 100 \mathrm{~mm} \times 0.5 \mathrm{~mm}$ sheets after compression moulding at $180^{\circ} \mathrm{C}$. Extensional rheology was measured using a Sentmanat Extensional Rheometer (SER-HPV 1, Xpansion instruments, Tallmadge, OH, USA) for Anton Paar rheometers, at $180^{\circ} \mathrm{C}$ and five different strain rates $\left(\dot{\varepsilon}=10 ; 3 ; 1 ; 0.3 ; 0.1 \mathrm{~s}^{-1}\right)$. The strain hardening ratio SHR was calculated using the maximum value of the elongational viscosity $\eta_{\mathrm{Emax}}^{+}$for every strain rate and the corresponding value at time $t$ from the threefold of the linear viscoelastic start up curve.

$$
S H R=\frac{\eta_{\mathrm{Emax}}^{+}(t, \dot{\varepsilon})}{3 \eta^{+}(t)}
$$




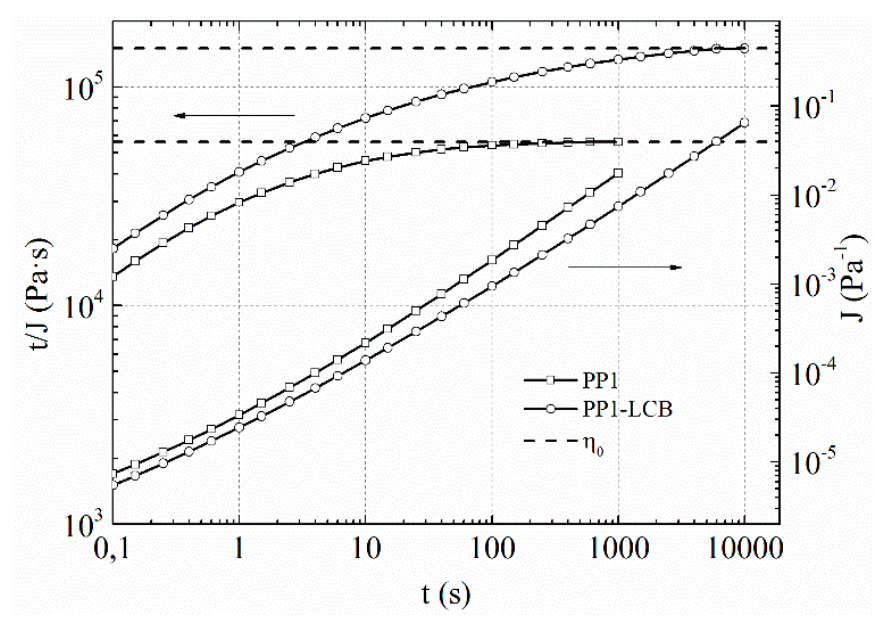

Figure 3. Creep experiments and determination of $\eta_{0}$.

\subsection{Sample Preparation}

Particles with a mean diameter of $1 \mathrm{~mm}$ were formed by shredding virgin PP granules with a Fritsch granulator "Pulverisette 16, Fritsch, Idar-Oberstein, Germany". From the literature it is known that stabiliser systems (especially hindered amine light stabilisers and sulphur-containing additives) can influence the melt modification of PP [28,50]. Therefore, the oxidation induction time (OIT) of the polypropylene grades was determined to compare the oxidative behaviour of the materials. PP1 for pipes and PP4 for injection moulding had an OIT longer than 90 min (Figure 4). To minimise possible side effects, the stabilisers were washed out of the grinded polymers PP1, PP2 and PP3 by Soxhlet extraction overnight with acetone. In the case of PP4, it was necessary to repeat the procedure with dichloromethane. The OIT of the industrial grade and after Soxhlet extraction are summarised in Table 2.

A solution of the PODIC in $50 \mathrm{ml} n$-hexane was purified on the destabilised grinded polymer, mixed and then stored at room temperature until the solvent evaporated. Reactive extrusion was carried out in a Haake Mini Lab II conically shaped twin-screw extruder at $180{ }^{\circ} \mathrm{C}$ and with $100 \mathrm{rpm}$ screw speed for $5 \mathrm{~min}$. After $4 \mathrm{~min}$, when the PODIC should be completely decomposed (estimated from the half-life), $1 \mathrm{mg}$ (about 0.02\%) Irganox 1010 (BASF, Ludwigshafen, Germany) was added in order to prevent further degradation.

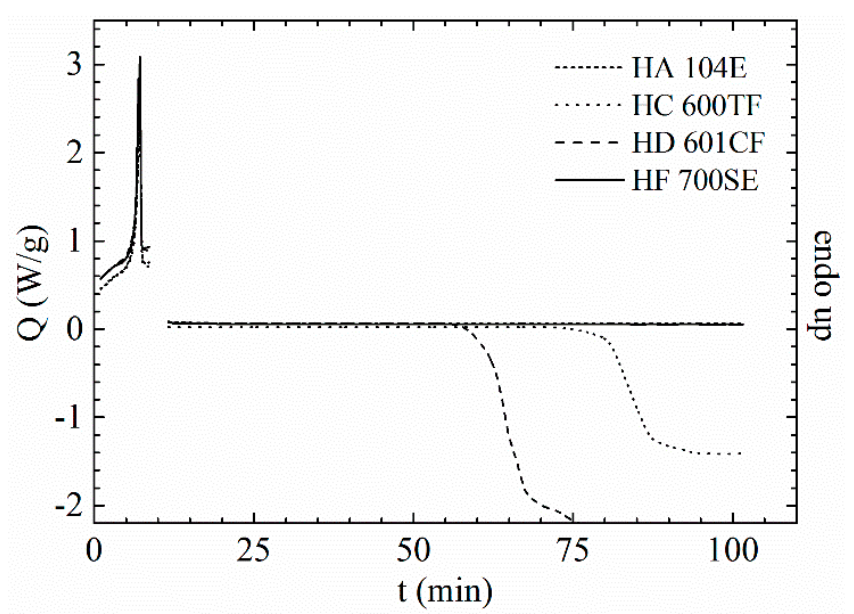

Figure 4. Comparison of the OIT of the shredded PP granules. 
Table 2. OIT before and after Soxhlet extraction of the PPs.

\begin{tabular}{ccc}
\hline & OIT & OIT \\
\cline { 2 - 3 } Sample & Industrial Grade & after Soxhlet \\
\cline { 2 - 3 } & [min] & [min] \\
\hline PP1 & $>90$ & 17 \\
PP2 & 67 & 9 \\
PP3 & 48 & 10 \\
PP4 & $>90$ & 11 \\
\hline
\end{tabular}

\section{Results and Discussion}

\subsection{Thermal Analysis}

The degree of crystallinity of semi-crystalline polymers depends-besides the processing conditions-on the molar mass and the structural regularity of a given polymer. It can be reflected by the enthalpy of fusion $\Delta H_{\mathrm{m}}$, and the melting temperature $T_{\mathrm{m}}$ and is reduced by the introduction of non-crystallising structural units such as branches and grafts [48]. During the radical induced melt modification of PP, degradation and recombination take place simultaneously, which results in a higher $M_{\mathrm{W}}$, a broadening of MMD and more chain irregularity. Therewith the crystallisation behaviour of the LCB-PP is affected. Wang et al. described the crystallisation behaviour of LCB-PP prepared by grafting of pentaerythritol triacrylate (PETA). They suggested that the small number of branching points in LCB-PP increases the nucleation density, which results in higher $T_{\mathrm{c}}$ [51]. Compared to its linear precursor, Tian et al. calculated smaller Avrami exponents for LCB-PP, which was also prepared by grafting with PETA. They concluded that LCB acts as a heterogeneous nucleating agent and influences the mechanism and the growth of PP crystals [52]. Also, Nam et al. suggested irregularities induced by long-chain branching to broaden the melting peak of the LCB-PP [39]. Tabatabei et al. studied blends of linear and LCB-PP, and postulated that even a small amount of LCB increases the number of nuclei sites, resulting in an increase of crystallinity. However, an increased number of branches prevents chain mobility, leading to a decrease in crystallinity (20\% of LCB-PP in the blend) [53]. Nevertheless, $\Delta H_{\mathrm{m}}, T_{\mathrm{m}}$ and $T_{\mathrm{c}}$ increased for all samples (shown in Figure 5).

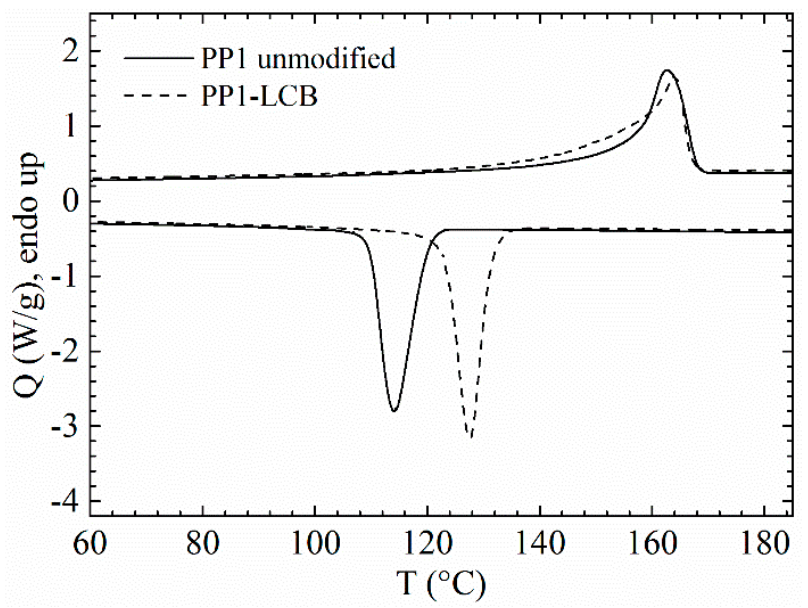

Figure 5. Changes in thermal properties for linear and LCB-PP1.

The extent of the increase of $\Delta H_{\mathrm{m}}$, decreases from PP1-LCB over PP2-LCB and PP3-LCB to PP4-LCB and therefore so does the effect of PODIC modification on the crystallisation behaviour.

As can be seen in Table 3, the extent of the increase of $\Delta H_{\mathrm{m}}$ decreases from PP1-LCB over PP2-LCB and PP3-LCB to PP4-LCB. Therefore, the effect of PODIC modification on the crystallisation behaviour 
is more pronounced in a high molar mass grade PP compared to the injection-moulding grade, with an innately high ability to crystallise.

Table 3. Thermal properties of the studied polymer samples.

\begin{tabular}{cccc}
\hline Sample & $\boldsymbol{T}_{\mathrm{m}}\left[{ }^{\circ} \mathrm{C}\right]$ & $\boldsymbol{T}_{\mathbf{c}}\left[{ }^{\circ} \mathrm{C}\right]$ & $\Delta \boldsymbol{H}_{\mathrm{m}}\left[\mathbf{J} \cdot \mathbf{g}^{-\mathbf{1}}\right]$ \\
\hline PP 1 & 163 & 114 & 90 \\
PP 1-LCB & 164 & 128 & 98 \\
PP 2 & 161 & 113 & 92 \\
PP 2-LCB & 163 & 128 & 98 \\
PP 3 & 162 & 115 & 93 \\
PP 3-LCB & 163 & 128 & 99 \\
PP 4 & 162 & 114 & 98 \\
PP 4-LCB & 163 & 127 & 101 \\
\hline
\end{tabular}

Further conclusions relating changes of the polymer structure (e.g., an average number of branches per molecule) cannot be drawn from the DSC data, but it is a fast and reliable method and gives a hint of the success of the LCB reaction.

\section{2. $M M D$ and $L C B$ of the PP Samples}

The weight average molar mass, the number average molar mass, and the polydispersity indices and the number of branches per molecule are summarised in Table 4. The MMD of all polymer samples is shown in Figure 6. The LCB samples (dashed lines) show a distinctive shoulder in the high molar mass region. This shoulder looks more pronounced when the linear PP has a higher molar mass. $M_{\mathrm{W}}$ and $M_{\mathrm{w}} / M_{\mathrm{n}}$ thus increased for all samples. Additionally, the peak maximum of the MMD of PP1-LCB was distinctively reduced and the peak also broadens in the region of smaller molar masses.

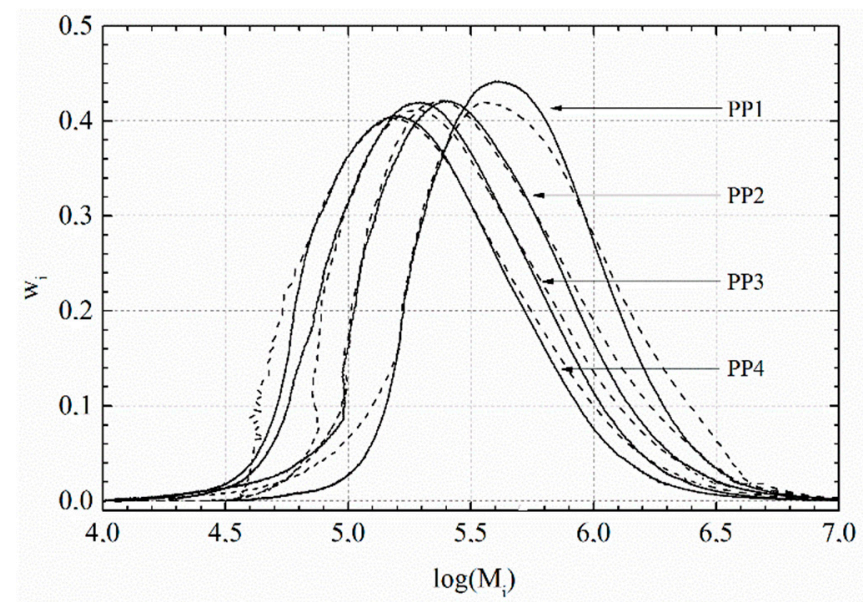

Figure 6. MMD of the linear PP samples (compact lines) and the LCB samples (dashed lines).

The branched structure of the LCB-samples can be detected from the Mark-Houwink plot in Figure 7, by comparing the solution of the LCB-sample with its linear precursor under the condition of a similar molar mass. Comparison with a linear equivalent should also enable the quantification as well as the detection of branching. In Table 4, the average number of branches per molecule $B_{\mathrm{n}}$ was calculated according to the model of Zimm and Stockmeyer [54,55], using the method of Lecacheux et al. [56]. This method has a number of limitations, but allows for an accurate quantification of branching, e.g., for PE [57,58], and is therefore also commonly used for PP. 


$$
g=\left(\frac{[\eta]_{\mathrm{b}}}{[\eta]_{1}}\right)^{\frac{1}{\epsilon}}
$$

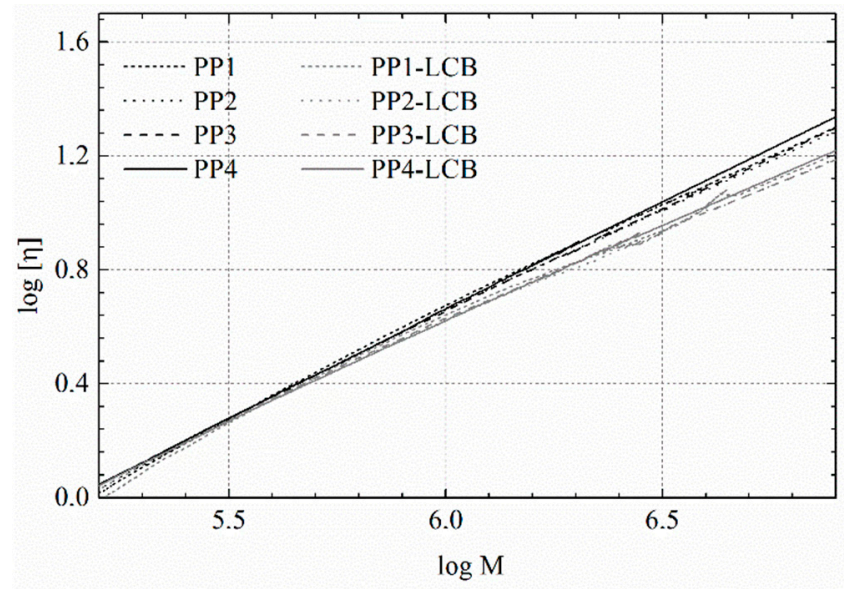

Figure 7. Intrinsic viscosity as a function of the molar mass of the linear PPs (black lines) and the LCB PPs (grey).

The ratio of the mean square radii of gyration $g$ was calculated from the intrinsic viscosity of the branched $[\eta]_{b}$ and the linear $[\eta]_{1}$ polymer. The parameter $\epsilon$ depends on the type of branched structure and the solvent-polymer interaction. In the literature, $\epsilon$ has a value of 0.5 for star polymers, 1.5 for combs with large backbones and short branches, and 0.7 for multi-arm stars [59-61]. For LCB-PP a value of $\epsilon=0.75$ is often used in the literature $[40,62,63]$. $B_{n}$ was calculated by solving the following equation and the results are summarised in Table 4:

$$
g=\left[\left(1+\frac{B_{\mathrm{n}}}{7}\right)^{\frac{1}{2}}+\frac{4 B_{\mathrm{n}}}{9 \pi}\right]^{-\frac{1}{2}} .
$$

Table 4. Molar masses, polydispersity and branching number of the LCB-PPs.

\begin{tabular}{ccccc}
\hline Sample & $\boldsymbol{M}_{\mathbf{w}}\left[\mathbf{k g ~ \mathbf { ~ m o l } ^ { - \mathbf { 1 } } ]}\right.$ & $\boldsymbol{M}_{\mathbf{n}}\left[\mathbf{k g ~ \mathbf { ~ m o l } ^ { - \mathbf { 1 } } ]}\right.$ & $\boldsymbol{M}_{\mathbf{w}} \boldsymbol{M}_{\mathbf{n}}$ & $\boldsymbol{B}_{\mathbf{n}}$ \\
\hline PP1-LCB & 611 & 317 & 1.92 & 0.08 \\
PP2-LCB & 436 & 196 & 2.22 & 0.13 \\
PP3-LCB & 333 & 151 & 2.20 & 0.25 \\
PP4-LCB & 264 & 106 & 2.49 & 0.27 \\
\hline
\end{tabular}

The results in Table 4 show that $B_{\mathrm{n}}$ increases, with a decrease of the molar mass of the linear PP. According to the reaction scheme in Figure 1, PP1 (with high molar mass) forms larger chain fragments with reduced ability for recombination during LCB due to lower chain mobility, which is in accordance with [64]. This results in a decreasing branching number $B_{\mathrm{n}}$ and longer side arms with a higher molar mass. The prevalence of LCB (and increasing $B_{\mathrm{n}}$ ) seems enhanced, with a lower molar mass of the linear unmodified PP.

\subsection{Dynamic Rheology}

The linear viscoelastic behaviour of a polymer melt is sensitive to structural changes of macromolecules, especially to LCB. Therefore, the comparison of dynamic moduli is a well-established technique to show the structural changes of a polymer. LCB primarily influences the elastic behaviour and therefore the storage modulus of the polymer samples in the low-frequency regime. The storage 
moduli of linear precursors and the LCB-PPs are presented in Figure 8. According to the predictions of Fleissner et al., changes in $M_{\mathrm{W}}$ and MMD (e.g., induced by the LCB) influence the position of the modulus crossover point [65]. The crossover modulus of all samples decreases with LCB (broadening of MMD) and the crossover frequency shifts towards smaller values (higher $M_{\mathrm{W}}$ ). Except for PP1, its crossover frequency shifts towards a slightly higher value (smaller $M_{\mathrm{W}}$ ), which is in accordance with the data from SEC.

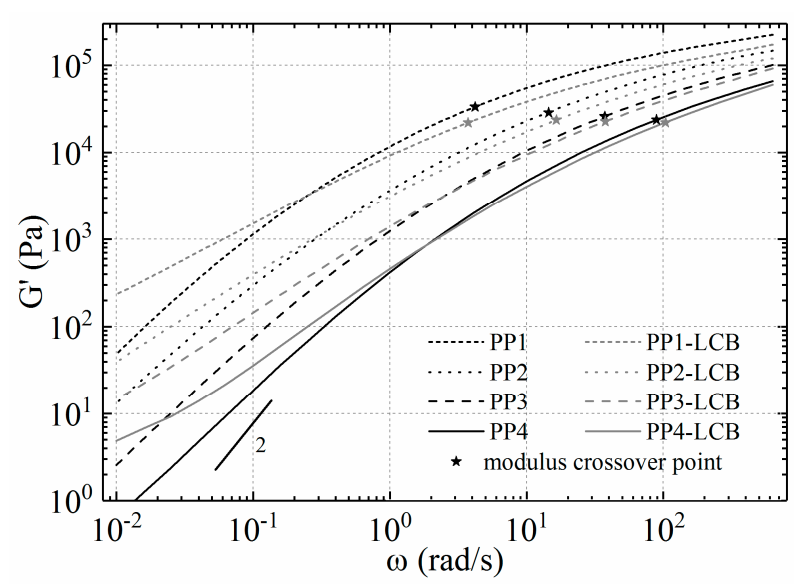

Figure 8. Storage moduli as a function of angular frequency at $180{ }^{\circ} \mathrm{C}$.

Additionally, the storage modulus of PP4-LCB shows a clear and PP3-LCB a slight deviation from the slope of 2 in the low frequency range, which may include a second elastic plateau. According to WoodAdams [61], such a second plateau is a further hint of the branched structure of the measured polymer. A plot of the loss angle $\delta$ and the complex modulus $\left|G^{*}\right|$ (van Gurp Palmen plot) offers the possibility to classify and quantify the amount and type of LCB with a linear reference of similar MMD [66,67]. The deviation from the linear reference depends strongly on the degree of LCB (which is shown in Figure 9 for PP2 and PP2-LCB). In our case a lightly LCB structure can be concluded from the plot.

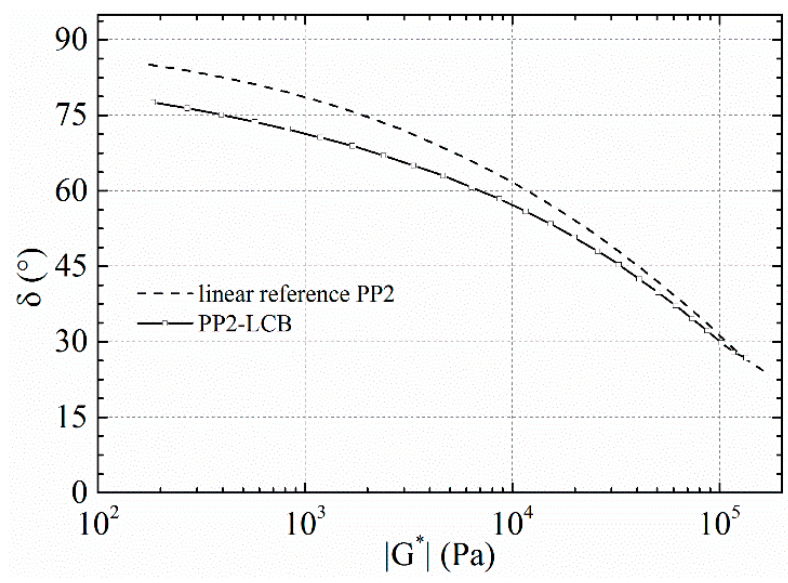

Figure 9. $\delta$ - $\left|G^{*}\right|$-plot of PP2 (linear reference) and PP2-LCB.

Further characteristic effects of a branched structure, when compared to a linear precursor, are a pronounced shear thinning at high shear and a higher viscosity at low shear. As can be seen in Figure 10, the linear PPs reach their zero-shear viscosity plateau between the frequency of $0.1 \mathrm{rad} \cdot \mathrm{s}^{-1}$ and $1 \mathrm{rad} \cdot \mathrm{s}^{-1}$, while the transition zone from power law to the zero-shear regime shifts to smaller frequencies and becomes broader for the LCB-PPs. The effect of shear thinning is more pronounced with PP1-LCB and decreases with diminishing molar mass. 


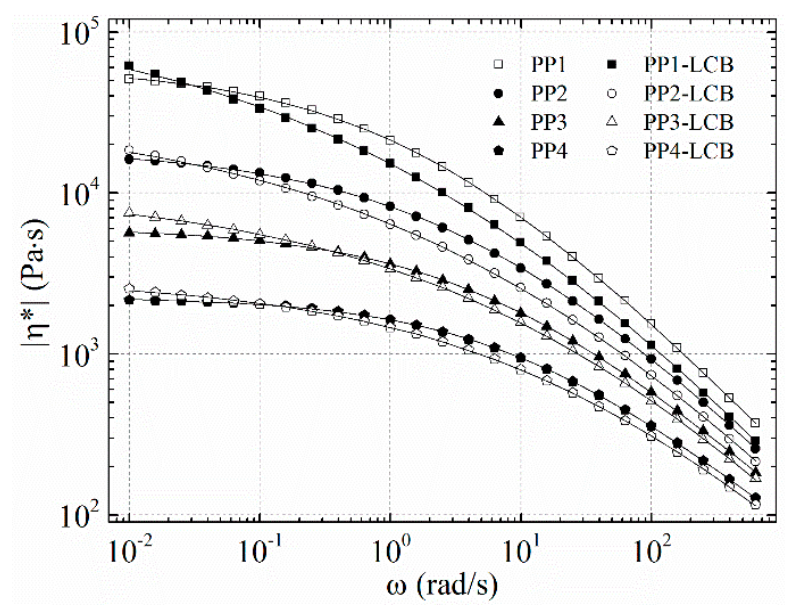

Figure 10. Dynamic viscosity as a function of angular frequency at $180{ }^{\circ} \mathrm{C}$ and the prediction of the Carreau-Yasuda model.

According to Tsenoglu et al., the branching number $B_{\mathrm{n}}$ can also be calculated from the measured zero-shear viscosity of the branched PP $\eta_{b}$ and the linear PP $\eta_{1}$, especially for LCB-PP prepared from a linear PP with PODIC [68]. The theory assumes that for sparsely branched polymers the number of branch points per molecule is either zero or one, and the melt is approximated to a blend of mostly linear with three-arm star-shaped chains with arm length half of the average length of the linear precursor. Under these assumptions, the fraction of branched molecules equals $B_{\mathrm{n}}$, which can be calculated with Equation (5):

$$
B_{\mathrm{n}}=\frac{\ln \left\{\frac{\eta_{\mathrm{b}}}{\eta_{\mathrm{l}}}\right\}}{\alpha\left[\frac{M_{\mathrm{L}}}{M_{\mathrm{C}}}-1\right]-3 \ln \left\{\frac{M_{\mathrm{L}}}{M_{\mathrm{C}}}\right\}} .
$$

In this equation $M_{\mathrm{L}}$ is the weight average molar mass of the linear PP, $M_{\mathrm{C}}$ the molecular weight at the onset of entanglements, which is equal twice of the molecular weight of two successive entanglements $\left(M_{C} \approx 2 M_{\mathrm{e}}\right)$, and the numerical coefficient $\alpha=0.42$. According to the tube model, $\alpha=15 / 8$, but experiments indicated a lower value of $\alpha \approx 0.43-0.60$ for star-shaped polymers [68]. In a later work, Gotsis et al. used a modified $\alpha=0.48$ for a LCB-PP with lower molar mass compared to their previous work and postulated that $\alpha$ is dependent on the molar mass and the molar mass distribution [35]. For PP1-LCB and PP2-LCB results of $B_{\mathrm{n}}$ were obtained with $\alpha=0.42$ similar to $B_{\mathrm{n}}$ from HT-SEC. For PP3-LCB and PP4-LCB $\alpha=0.42$ gave no satisfying results. Jørgensen et al., for example, needed to adapt $\alpha=0.8$ to get the best fit for their LCB-metallocene HDPE [69]. We also used adapted $\alpha$ values to get the best fit for PP3-LCB and PP4-LCB (results are shown in Table 5). However, the values are within the experimental values of $\alpha \approx 0.43-0.60$, which are given in the literature.

Table 5. Branching number from rheological data.

\begin{tabular}{cccc}
\hline Sample & $\boldsymbol{\eta}^{\mathbf{0}}[\mathbf{P a} \cdot \mathbf{s}]$ & $\boldsymbol{B}_{\mathbf{n}}$ & $\boldsymbol{\alpha}$ \\
\hline PP1-LCB & 150200 & 0.08 & 0.45 \\
PP2-LCB & 37100 & 0.13 & 0.46 \\
PP3-LCB & 11500 & 0.25 & 0.49 \\
PP4-LCB & 2730 & 0.27 & 0.52 \\
\hline
\end{tabular}

\subsection{Extensional Rheology}

Distinct differences in the elongational behaviour are related to changes in the molecular structure of the studied PP. LCB-PPs are able to build up a strong entangled network connected with strong nonlinear effects of the elongational viscosity called strain hardening. As can be seen in Figure 11, 
the linear PPs show no strain-hardening behaviour and no deviation from the linear viscoelastic start-up curve. Because of the low zero-shear viscosity of PP4 at the measuring temperature, it was not possible to measure the extensional viscosity at Hencky strain rates below $1 \mathrm{~s}^{-1}$.

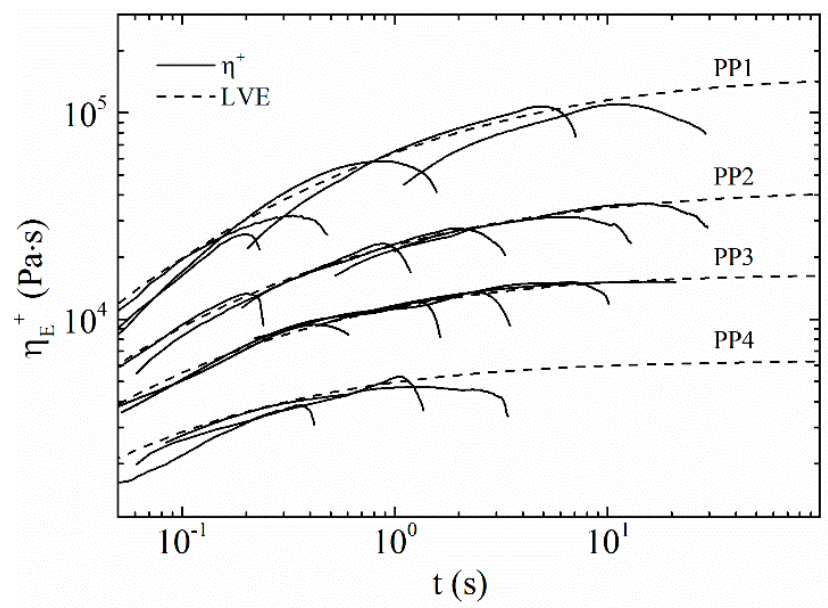

Figure 11. Extensional rheology of the linear PPs.

The modification with PODIC induced LCB to the linear polymer backbone and therefore strain-hardening behaviour was obtained for all LCB-PPs. (It has to be noted that PP3-LCB and PP4-LCB show slight sagging, which is, especially at lower strain rates, in competition with the strain hardening.) The SER curves are plotted in Figure 12 and the calculated corresponding strain-hardening ratios are given in Figure 13. The SHR increases with increasing $B_{\mathrm{n}}$, which can be seen in Figure 13 when the SHR at $\varepsilon=1 \mathrm{~s}^{-1}$ of PP1-LCB, PP2-LCB and PP3-LCB are compared. This is in agreement with the results from HT-SEC and the calculated $B_{\mathrm{n}}$. All samples show a dependency of the strain hardening on the strain rate. The SHR of PP1-LCB shows a slight decrease of SHR with increasing strain rate; this becomes clearer for PP3-LCB. The SHR of PP3-LCB and PP4-LCB first increase and reach their maximum at $\varepsilon=1 \mathrm{~s}^{-1}$ and then decrease again. According to Gabriel et al. [70], more pronounced strain hardening at the lower Hencky strain rate is a sign of fewer branches in the polymer, which is in agreement with the calculated $B_{\mathrm{n}}$. However, PP3-LCB and PP4-LCB do not exactly follow the observations from Gabriel at al. but lie between the predictions. This seems obvious because the $B_{\mathrm{n}}$ for PP3-LCB and PP4-LCB are not enough so speak from highly branched.

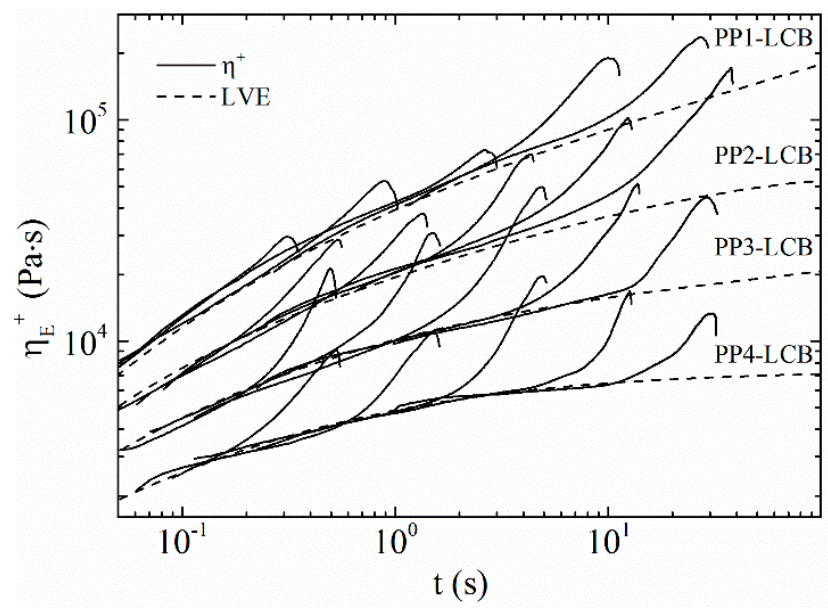

Figure 12. Extensional rheology of the LCB-PPs. 


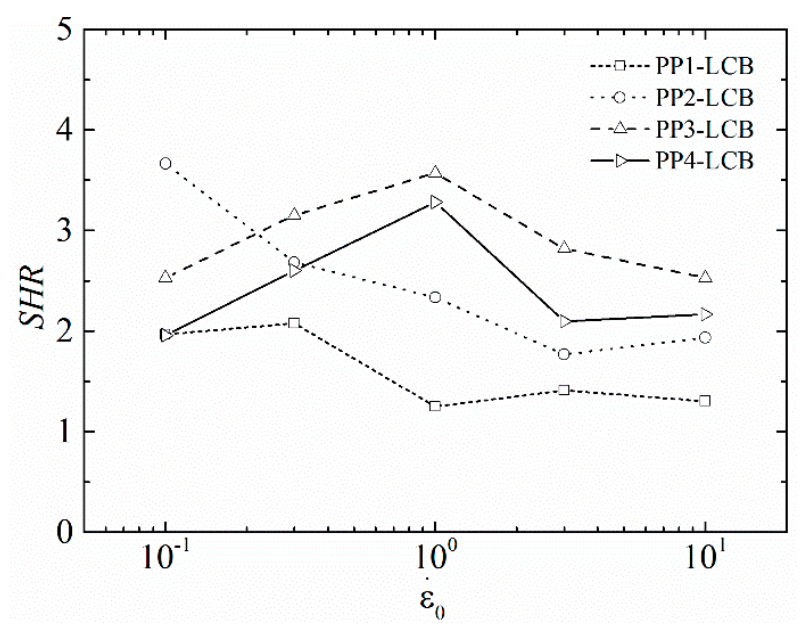

Figure 13. Strain hardening ratio of the LCB samples.

\section{Conclusions}

In this study a peroxydicarbonate (PODIC) with long aliphatic side chains was used for the LCB of different PP grades. The linear PPs differed in their average molar mass but had similar polydispersity indices. LCB-PPs were prepared via reactive extrusion in melt. The melt viscosity of the LCB-PPs showed classical effects such as an increase in melt elasticity and pronounced strain hardening, which is in agreement with the literature. Furthermore, strain-hardening behaviour was introduced to all LCB-PPs. A strain-hardening dependency of all samples was observed. PP1-LCB and PP2-LCB showed more pronounced strain hardening at low strain rates, which is typical of a low number of branches. LCB was proven by HT-SEC measurements and the deviation of the intrinsic viscosity of the branched samples from their linear PPs was shown. The average branching number per molecule was calculated according to the model of Zimm and Stockmeyer and showed a very low value for PP1-LCB (pipe grade) of 0.08; this value increases to 0.13 for PP2-LCB (from thermoforming grade), and to 0.25 and 0.27 for PP3-LCB (from casting grade) and PP4-LCB (injection moulding grade), respectively. The number average molar mass of PP1-LCB and PP2-LCB decreased compared to their linear feedstocks. Due to the radical reaction mechanism of the LCB, it is suggested that the recombination reaction and therefore the resulting LCB is inhibited by the higher molar mass of PP1. In contrast, the lower molar mass fragments of PP4 lead to a higher number of LCBs. These results will have to be considered for the upcycling of commingled PP single-polymer waste and will be the basis of further studies.

Acknowledgments: The authors thank Borealis for the provided PP samples. The authors acknowledge the TU Wien University Library for financial support through its Open Access Funding Programme.

Author Contributions: Florian Kamleitner designed and performed the experiments analysed the data and wrote the paper. Bernadette Duscher designed the concept of PP up-cycling and analysed the rheological data. Thomas Koch performed the thermal analysis and prepared the graphs. Simone Knaus guided the chemical part of this work. Klaus Schmid gave valuable advice in the mechanism of PODIC assisted long chain branching. Vasiliki-Maria Archodoulaki enabled and guided the project.

Conflicts of Interest: The authors declare no conflict of interest.

\section{References}

1. Pasquini, N.; Addeo, A. Polypropylene Handbook; Hanser: Cincinnati, OH, USA, 2005.

2. Plastics Europe. Plastics-The Facts; Plastics Europe-Association of Plastics Manufacturers: Brussels, Belgium, 2015.

3. Al-Salem, S.M.; Lettieri, P.; Baeyens, J. Recycling and recovery routes of plastic solid waste (psw): A review. Waste Manag. 2009, 29, 2625-2643. [CrossRef] [PubMed] 
4. Vilaplana, F.; Karlsson, S. Quality concepts for the improved use of recycled polymeric materials: A review. Macromol. Mater. Eng. 2008, 293, 274-297. [CrossRef]

5. Jolly, R.; Rhin, C. Recycling of materials in industry the recycling of lead-acid batteries: Production of lead and polypropylene. Resour. Conserv. Recycl. 1994, 10, 137-143. [CrossRef]

6. Da Costa, H.M.; Ramos, V.D.; de Oliveira, M.G. Degradation of polypropylene (pp) during multiple extrusions: Thermal analysis, mechanical properties and analysis of variance. Polym. Test. 2007, 26, 676-684. [CrossRef]

7. Da Costa, H.M.; Ramos, V.D.; Rocha, M.C.G. Rheological properties of polypropylene during multiple extrusion. Polym. Test. 2005, 24, 86-93. [CrossRef]

8. González-González, V.A.; Neira-Velázquez, G.; Angulo-Sánchez, J.L. Polypropylene chain scissions and molecular weight changes in multiple extrusion. Polym. Degrad. Stab. 1998, 60, 33-42. [CrossRef]

9. Garcia, P.S.; Scuracchio, C.H.; Cruz, S.A. Effect of residual contaminants and of different types of extrusion processes on the rheological properties of the post-consumer polypropylene. Polym. Test. 2013, 32, 1237-1243. [CrossRef]

10. Brandrup, J. Recycling and Recovery Of Plastics; Hanser Publisher: München Wien, Austria, 1996.

11. Goodship, V. Introduction to Plastic Recycling, 2nd ed.; Smithers Rapra Technology Ltd.: Shropshire, UK, 2007.

12. Siddique, R.; Khatib, J.; Kaur, I. Use of recycled plastic in concrete: A review. Waste Manag. 2008, 28, 1835-1852. [CrossRef] [PubMed]

13. Ha, K.H.; Kim, M.S. Application to refrigerator plastics by mechanical recycling from polypropylene in waste-appliances. Mater. Des. 2012, 34, 252-257. [CrossRef]

14. Teh, J.W.; Rudin, A.; Keung, J.C. A review of polyethylene-polypropylene blends and their compatibilization. Adv. Polym. Technol. 1994, 13, 1-23. [CrossRef]

15. Hettema, R.; Van Tol, J.; Janssen, L.P.B.M. In-situ reactive blending of polyethylene and polypropylene in co-rotating and counter-rotating extruders. Polym. Eng. Sci. 1999, 39, 1628-1641. [CrossRef]

16. Hettema, R.; Pasman, J.; Janssen, L.P.B.M. Reactive extrusion of recycled bottle waste material. Polym. Eng. Sci. 2002, 42, 665-680. [CrossRef]

17. $\mathrm{Gu}, \mathrm{J} . ; \mathrm{Xu}, \mathrm{H} . ; \mathrm{Wu}, \mathrm{C}$. The effect of benzoyl peroxide and divinyl benzene on the properties of crosslinked recycled polyolefin blends. J. Macromol. Sci. Part B 2013, 1777-1785.

18. Kim, B.K. Reactive extrusion of polyolefins and their blends. Korea Polym. J. 1996, 4, 215-226.

19. Braun, D.; Richter, S.; Hellmann, G.P.; Rätzsch, M. Peroxy-initiated chain degradation, crosslinking, and grafting in pp-pe blends. J. Appl. Polym. Sci. 1998, 68, 2019-2028. [CrossRef]

20. Borsig, E.; Fiedlerová, A.; Rychlá, L.; Lazár, M.; Rätzsch, M.; Haudel, G. Crosslinking of polypropylene-polyethylene blends by peroxide and the effect of pentaerythritol tetrallyl ether. J. Appl. Polym. Sci. 1989, 37, 467-478. [CrossRef]

21. Chodak, I. Improving the properties of polyolefin waste by reactive processing. Polym. Plast. Technol. Eng. 2004, 43, 1769-1777. [CrossRef]

22. Kruliš, Z.; Kokta, B.V.; Horák, Z.; Michálková, D.; Fortelný, I. Compatibilization as a procedure for recycling of commingled polyolefin waste. Macromol. Mater. Eng. 2001, 286, 156-160. [CrossRef]

23. Hernández-Ortiz, J.C.; Van Steenberge, P.H.M.; Reyniers, M.-F.; Marin, G.B.; D’Hooge, D.R.; Duchateau, J.N.E.; Remerie, K.; Toloza, C.; Vaz, A.L.; Schreurs, F. Modeling the reaction event history and microstructure of individual macrospecies in postpolymerization modification. AIChE J. 2017. [CrossRef]

24. Passaglia, E.; Coiai, S.; Cicogna, F.; Ciardelli, F. Some recent advances in polyolefin functionalization. Polym. Int. 2014, 63, 12-21. [CrossRef]

25. Parent, J.S.; Bodsworth, A.; Sengupta, S.S.; Kontopoulou, M.; Chaudhary, B.I.; Poche, D.; Cousteaux, S. Structure-rheology relationships of long-chain branched polypropylene: Comparative analysis of acrylic and allylic coagent chemistry. Polymer 2009, 50, 85-94. [CrossRef]

26. Zhang, W.; Yang, L.; Zhang, H.; Lin, W.; Wang, Y. Investigation on multifunctional monomer modified polypropylene and its foamability. J. Appl. Polym. Sci. 2013, 130, 1675-1681. [CrossRef]

27. Zulli, F.; Andreozzi, L.; Passaglia, E.; Augier, S.; Giordano, M. Rheology of long-chain branched polypropylene copolymers. J. Appl. Polym. Sci. 2013, 127, 1423-1432. [CrossRef]

28. Drooghaag, X.; Rousseaux, D.D.J.; Henry, G.R.P.; Sclavons, M.; Carlier, V.; Marchand-Brynaert, J. Mediated melt functionalization of polypropylene. Polym. Degrad. Stab. 2010, 95, 342-345. [CrossRef] 
29. Langston, J.A.; Colby, R.H.; Chung, T.C.M.; Shimizu, F.; Suzuki, T.; Aoki, M. Synthesis and characterization of long chain branched isotactic polypropylene via metallocene catalyst and t-reagent. Macromolecules 2007, 40, 2712-2720. [CrossRef]

30. Li, S.; Xiao, M.; Wei, D.; Xiao, H.; Hu, F.; Zheng, A. The melt grafting preparation and rheological characterization of long chain branching polypropylene. Polymer 2009, 50, 6121-6128. [CrossRef]

31. Diop, M.F.; Torkelson, J.M. Novel synthesis of branched polypropylene via solid-state shear pulverization. Polymer 2015, 60, 77-87. [CrossRef]

32. El Mabrouk, K.; Parent, J.S.; Chaudhary, B.I.; Cong, R. Chemical modification of pp architecture: Strategies for introducing long-chain branching. Polymer 2009, 50, 5390-5397. [CrossRef]

33. Wong, B.; Baker, W.E. Melt rheology of graft modified polypropylene. Polymer 1997, 38, 2781-2789. [CrossRef]

34. Zhang, Z.; Yu, F.; Zhang, H. Isothermal and non-isothermal crystallization studies of long chain branched polypropylene containing poly (ethylene-co-octene) under quiescent and shear conditions. Polymers 2017. [CrossRef]

35. Gotsis, A.D.; Zeevenhoven, B.L.F.; Tsenoglou, C. Effect of long branches on the rheology of polypropylene. J. Rheol. 2004, 48, 895-914. [CrossRef]

36. Auhl, D.; Stange, J.; Münstedt, H.; Krause, B.; Voigt, D.; Lederer, A.; Lappan, U.; Lunkwitz, K. Long-chain branched polypropylenes by electron beam irradiation and their rheological properties. Macromolecules 2004, 37, 9465-9472. [CrossRef]

37. Stange, J.; Münstedt, H. Rheological properties and foaming behavior of polypropylenes with different molecular structures. J. Rheol. 2006, 50, 907-923. [CrossRef]

38. Härth, M.; Kaschta, J.; Schubert, D.W. Shear and elongational flow properties of long-chain branched poly(ethylene terephthalates) and correlations to their molecular structure. Macromolecules 2014, 47, 4471-4478. [CrossRef]

39. Nam, G.J.; Yoo, J.H.; Lee, J.W. Effect of long-chain branches of polypropylene on rheological properties and foam-extrusion performances. J. Appl. Polym. Sci. 2005, 96, 1793-1800. [CrossRef]

40. Lagendijk, R.P.; Hogt, A.H.; Buijtenhuijs, A.; Gotsis, A.D. Peroxydicarbonate modification of polypropylene and extensional flow properties. Polymer 2001, 42, 10035-10043. [CrossRef]

41. Gotsis, A.D.; Zeevenhoven, B.L.F.; Hogt, A.H. The effect of long chain branching on the processability of polypropylene in thermoforming. Polym. Eng. Sci. 2004, 44, 973-982. [CrossRef]

42. Buback, M.; Frauendorf, H.; Janssen, O.; Vana, P. Electrospray ionization mass spectrometric study of end-groups in peroxydicarbonate-initiated radical polymerization. J. Polym. Sci. Part A Polym. Chem. 2008, 46, 6071-6081. [CrossRef]

43. Hogt, A.H.; Spijkerman, G.K. Extrusion Process for Enhancing the Melt Strength of Polypropylene. Patent WO1999027007 A1, 3 June 1999.

44. Kamleitner, F.; Duscher, B.; Koch, T.; Knaus, S.; Archodoulaki, V.M. Upcycling of polypropylene-The influence of polyethylene impurities. Polym. Eng. Sci. 2017, doi:10.1002/pen.24522.

45. Kamleitner, F.; Duscher, B.; Koch, T.; Knaus, S.; Archodoulaki, V.M. Long chain branching as an innovative up-cycling process of polypropylene post-consumer waste-possibilities and limitations. Waste Manag. 2017. submitted. [CrossRef] [PubMed]

46. Martins, M.H.; De Paoli, M.-A. Polypropylene compounding with recycled material i Statistical response surface analysis. Polym. Degrad. Stab. 2001, 71, 293-298. [CrossRef]

47. Valenza, A.; La Mantia, F.P. Recycling of polymer waste: Part II-Stress degraded polypropylene. Polym. Degrad. Stab. 1988, 20, 63-73. [CrossRef]

48. Mark, J.E. Physical Properties of Polymers Handbook; Springer: Berlin, Germany, 2007; Volume 1076.

49. DIN. Plastics_Dynamic Scanning Calorimetry (DSC)_Determination of the Oxidation Induction Time (OIT); BEUTH Verlag GmbH: Berlin, Germany, 2013; Volume 11357-6.

50. Pfaendner, R. Nitroxyl radicals and nitroxylethers beyond stabilization: Radical generators for efficient polymer modification. C. R. Chim. 2006, 9, 1338-1344. [CrossRef]

51. Wang, X.; Tzoganakis, C.; Rempel, G.L. Chemical modification of polypropylene with peroxide/ pentaerythritol triacrylate by reactive extrusion. J. Appl. Polym. Sci. 1996, 61, 1395-1404. [CrossRef]

52. Tian, J.; Yu, W.; Zhou, C. Crystallization behaviors of linear and long chain branched polypropylene. J. Appl. Polym. Sci. 2007, 104, 3592-3600. [CrossRef] 
53. Tabatabaei, S.H.; Carreau, P.J.; Ajji, A. Rheological and thermal properties of blends of a long-chain branched polypropylene and different linear polypropylenes. Chem. Eng. Sci. 2009, 64, 4719-4731. [CrossRef]

54. Zimm, B.H.; Stockmayer, W.H. The dimensions of chain molecules containing branches and rings. J. Chem. Phys. 1949, 17, 1301-1314. [CrossRef]

55. Zimm, B.H.; Kilb, R.W. Dynamics of branched polymer molecules in dilute solution. J. Polym. Sci. 1959, 37, 19-42. [CrossRef]

56. Lecacheux, D.; Lesec, J.; Quivoron, C. High-temperature coupling of high-speed gpc with continuous viscometry. I. Long-chain branching in polyethylene. J. Appl. Polym. Sci. 1982, 27, 4867-4877. [CrossRef]

57. Gaborieau, M.; Castignolles, P. Size-exclusion chromatography (sec) of branched polymers and polysaccharides. Anal. Bioanal. Chem. 2011, 399, 1413-1423. [CrossRef] [PubMed]

58. Provder, T. Chromatography of Polymers; American Chemical Society: Washington, DC, USA, 1993; Volume 521, p. 356.

59. Berry, G. Thermodynamic and conformational properties of polystyrene. III. Dilute solution studies on branched polymers. J. Polym. Sci. Part B Polym. Phys. 1971, 9, 687-715. [CrossRef]

60. Roovers, J.; Toporowski, P.; Martin, J. Synthesis and characterization of multiarm star polybutadienes. Macromolecules 1989, 22, 1897-1903. [CrossRef]

61. Wood-Adams, P.M.; Dealy, J.M.; deGroot, A.W.; Redwine, O.D. Effect of molecular structure on the linear viscoelastic behavior of polyethylene. Macromolecules 2000, 33, 7489-7499. [CrossRef]

62. Guapacha, J.; Vallés, E.M.; Quinzani, L.M.; Failla, M.D. Long-chain branched polypropylene obtained using an epoxy resin as crosslinking agent. Polym. Bull. 2016, 74, 1-22. [CrossRef]

63. Zhou, S.; Wang, W.; Zhao, S.; Xin, Z.; Shi, Y. Shear-induced $\beta$-form polypropylene in long chain branching isotactic polypropylene. Polym. Eng. Sci. 2016, 56, 240-247. [CrossRef]

64. Litvinov, V.M.; Ries, M.E.; Baughman, T.W.; Henke, A.; Matloka, P.P. Chain entanglements in polyethylene melts. Why is it studied again? Macromolecules 2013, 46, 541-547. [CrossRef]

65. Fleissner, M. Characterization of polymer molecular mass distribution from rheological measurements. Makromol. Chem. Macromol. Symp. 1992, 61, 324-341. [CrossRef]

66. Trinkle, S.; Friedrich, C. Van gurp-palmen-plot: A way to characterize polydispersity of linear polymers. Rheol. Acta 2001, 40, 322-328. [CrossRef]

67. Trinkle, S.; Walter, P.; Friedrich, C. Van gurp-palmen plot II-Classification of long chain branched polymers by their topology. Rheol. Acta 2002, 41, 103-113. [CrossRef]

68. Tsenoglou, C.J.; Gotsis, A.D. Rheological characterization of long chain branching in a melt of evolving molecular architecture. Macromolecules 2001, 34, 4685-4687. [CrossRef]

69. Jørgensen, J.K.; Stori, A.; Redford, K.; Ommundsen, E. Introduction of long-chain branches in linear polyethylene by light cross-linking with 1,3-benzenedisulfonyl azide. Polymer 2005, 46, 12256-12266. [CrossRef]

70. Gabriel, C.; Münstedt, H. Strain hardening of various polyolefins in uniaxial elongational flow. J. Rheol. 2003, 47, 619-630. [CrossRef]

(C) 2017 by the authors. Licensee MDPI, Basel, Switzerland. This article is an open access article distributed under the terms and conditions of the Creative Commons Attribution (CC BY) license (http:// creativecommons.org/licenses/by/4.0/). 